* Luís Fernando Sgarbossa: Doutor em Direito pela UFPR. Mestre em Direito pela mesma Instituição. Professor e Coordenador do Curso de Direito das Faculdades SECAL (Ponta Grossa - PR). Professor de pós-graduação da Escola da Magistratura do Paraná EMAP (Ponta Grossa - PR), da Academia Brasileira de Direito Constitucional ABDConst (Curitiba - PR) e do Instituto de Direito Constitucional e Cidadania - IDCC ( $\left.\begin{array}{llllllll}\mathrm{L} & \mathrm{o} & \mathrm{n} & \mathrm{d} & \mathrm{r} & \mathrm{i} & \mathrm{n} & \mathrm{a}\end{array}\right)$. lfsgarbossa@uol.com.br

** Geziela Iensue: Doutoranda em Direito pela UFPR. Mestre em Ciências Sociais Aplicadas pela UEPG. Professora e Coordenadora de Curso Adjunta do Curso de Direito das Faculdades SECAL. geziela@terra.com.br

\section{Existem normas constitucionais desprovidas de sanção?}

\section{There ARE CONSTITUTIONAL RULES DEVOID OF SANCTION?}

\author{
Luís Fernando Sgarbossa * \\ Geziela Iensue **
}

Resumo: O presente artigo explora o tema da existência ou inexistência de normas constitucionais desprovidas de sanção em virtude de seu impacto no que se refere à efetividade das normas constitucionais e à própria concepção acerca de sua força normativa. Após breves referências à polêmica entre sancionistas e não-sancionistas, evidencia a necessária distinção entre dispositivo e norma. Sustenta, ao final, a existência de uma sanção genérica das normas constitucionais, consistente na invalidade decorrente da inconstitucionalidade das normas infraconstitucionais desconformes para com a Constituição, refutando a possibilidade de se falar com propriedade em normas constitucionais desprovidas de sanção.

Palavras-chave: Normas constitucionais. Inconstitucionalidade. Sanção genérica.

Abstract: This article explores the issue of the presence or absence of constitutional rules deprived of sanctions and how sanctions impact the effectiveness of constitutional norms and even the conception of their normative power. After brief references to the controversy between sanctionists and nonsanctionists it righlights the distinction between text and norm. It maintains, in the end, the existence of a generic sanction of constitutional norms, consisting in the invalidity derived from the unconstitutionality of the infra-constitutional norms that do not comply with the Constitution, refusing the possibility of constitutional norms devoid of sanction.

Keywords: Constitutional norms. Unconstitutional laws. Generic sanction. 


\section{INTRODUÇÃO}

O presente artigo propõe-se a investigar um ponto controvertido na Teoria do Direito e na Teoria Constitucional, a saber, o da natureza das normas constitucionais no que se refere à existência ou inexistência de sanção a guarnecê-las e reforçá-las.

O tema é da maior relevância, posto que a normatividade constitucional e a efetividade dos comandos da Constituição dependem, em grande parte, da existência ou inexistência de sanção por seu descumprimento, bem como da natureza de tal sanção (TAVARES, 2005, p.63).

Ademais, a ideia de que as normas constitucionais não são garantidas por sanção acaba por induzir a uma concepção que aqui se julga errônea, na medida em que se passa a concebê-las como normas imperfeitas ou com baixa densidade normativa, o que favoreceria o reavivamento de teorias que buscam classificar as normas constitucionais em diferentes graus de normatividade, orientação esta que tem sido rechaçada pelas tendências mais recentes no Direito Constitucional.

Investigar-se-á, portanto, o que se tem entendido quanto à existência ou inexistência de normas constitucionais desprovidas de sanção, bem como o impacto de tais entendimentos no que se refere à juridicidade e mesmo à eficácia das normas estabelecidas pela Constituição.

\section{RELAÇÕES ENTRE NORMA E SANÇÃO}

É antigo o debate entre sancionistas e não-sancionistas, os primeiros concebendo a sanção como elemento essencial da norma jurídica, os segundos sustentando sua prescindibilidade.

A relação entre norma e sanção (MONTORO, 2005, p.538) ${ }^{1}$ é intuitivamente essencial: considerando que é da natureza de qualquer norma a possibilidade de seu descumprimento - posto que ordenar o necessário é absurdo - e considerando que o estabelecimento de um comando dá-se, em regra, pela necessidade de conter comportamentos existentes em sentido

\footnotetext{
${ }^{1}$ A temática da sanção remete, evidentemente, à temática da proteção jurídica, como evidencia André Franco Montoro. Como observa este autor, "o direito subjetivo ou a relação jurídica são tutelados pelo Estado, através de uma proteção especial, representada, de uma forma geral, pelo ordenamento jurídico e, particularmente, pela 'sanção’”. Observe-se que a coação (aplicação forçada da sanção) não se confunde com a própria sanção.
}

REVISTA DO DIREITO PÚBLICO, Londrina, v.9, n.1, p.163-178, jan./abr.2014 
oposto (HART, 2009, p.281), todos os sistemas normativos baseiam-se na ideia de sanção (KELSEN, 2003, p.38)², embora, evidentemente, a sanção jurídica seja diversa de outros tipos de sanção, como a social ou a moral (KELSEN, 2003, p.30).

A sanção, em sentido jurídico, pode ser compreendida como a consequência jurídica decorrente do não cumprimento de uma obrigação ou de um dever estabelecido pelo direito (MONTORO, 2005, p.538-539).

Assim, de um lado uma norma que determine que "é proibido esconder a lua” é teratológica e mesmo uma não-norma. Por outro lado, encontrandose o comando deontológico dentro do âmbito do possível, seu descumprimento é dele indissociável, consistindo em uma possibilidade sempre latente, razão da valorização da sanção como mecanismo de desestímulo da conduta (ou de estímulo, no caso das sanções positivas, que aqui não abordaremos por fugir ao escopo do trabalho) ou de restabelecimento da ordem jurídica violada (BOBBIO, 2007).

A relação entre norma e sanção foi a tal ponto valorizada que, como é sabido, para alguns autores e escolas do pensamento jurídico, ditos sancionistas, norma sem sanção é algo como uma "não-norma". Na teoria jurídica chegou-se mesmo a se atribuir maior importância ao denominado preceito secundário, estatuidor da sanção pelo descumprimento do comando deôntico (MONTORO, 2008, p.539), do que ao próprio preceito primário, estatuidor da conduta juridicamente devida, o que parece um tanto quanto exagerado (KELSEN, 1986, p.181). ${ }^{3}$

\footnotetext{
${ }^{2} \mathrm{O}$ próprio Hans Kelsen reconhece na Teoria Pura que a sanção psicológica, por exemplo, não é monopólio da ordem jurídica, mas que esta tem como peculiaridade de estatuir "atos de coação, designadamente a privação coercitiva da vida, da liberdade, de bens econômicos e outros, como consequência dos pressupostos por ele estabelecidos.” Pouco antes, ao indagar sobre a existência ou inexistência de ordens sociais desprovidas de sanção, Kelsen afirma o mesmo, ou seja, que a diferença não reside na presença ou ausência de sanções, mas na espécie das sanções cominadas. ${ }^{3}$ A importância atribuída por Kelsen ao que aqui denominamos preceito secundário (estatuidor de sanção) é tamanha que originalmente (na Teoria Pura) o austríaco chamava o preceito estatuidor de sanção de preceito primário, e o preceito que estabelecia a conduta de preceito secundário. Posteriormente, em sua Teoria Geral das Normas, o próprio Kelsen revê o posicionamento, adotando a terminologia que é aqui adotada: preceito primário como estatuidor da conduta devida e preceito secundário como estatuidor da sanção aplicável em caso de descumprimento da conduta devida. In verbis, o próprio Kelsen: "Se se admite que a distinção de uma norma que prescreve uma conduta determinada e de uma norma que prescreve uma sanção para o fato da violação da primeira seja essencial para o Direito, então precisa-se qualificar a primeira como norma primária e a segunda como secundária - e não o contrário, como foi por mim anteriormente formulado.”
} 
De qualquer modo, há que se reconhecer que a relação entre norma e sanção é importante (HART, 2009, p.280) ${ }^{4}$, e que a existência ou inexistência de sanções juridicamente impostas e de caráter coercitivo parece constituir uma das bases distintivas de âmbitos distintos do jurídico, como o âmbito do político (HART, 2009, p.105). ${ }^{5}$

Nada obstante, a doutrina reiteradamente aponta a existência de normas jurídicas em geral, e de normas constitucionais, em particular, desprovidas de sanção, buscando explicações para o fenômeno. Bobbio, por exemplo, aborda o problema em sua Teoria della Norma Giuridica, afirmando textualmente:

“O argumento mais comum e também mais fácil contra a teoria que vê na sanção um dos elementos constitutivos de um ordenamento jurídico é o que se funda na presença, em todo ordenamento jurídico, de normas não garantidas por sanção. Não há dúvida de que existem, em todo ordenamento jurídico, normas de que ninguém saberia indicar qual é a consequência desagradável imputada em caso de violação.” (BOBBIO, 2005, p.166)

\footnotetext{
${ }^{4}$ Neste diapasão convém recordar que H. L. A. Hart em sua obra The Concept of Law explora tal problema evidenciando as discussões sobre o caráter vinculante e mesmo jurídico do Direito Internacional. Nas palavras de Hart, "Como mostram as discussões encontradas nos livros, uma das fontes de dúvida sobre este ponto é simplesmente o fato de que o sistema carece de sanções centralmente organizadas. (...) A partir daí, a argumentação é simples: se, por essa razão, as normas do direito internacional não são 'vinculantes', é realmente indefensável levar a sério sua classificação como direito(...)".

${ }^{5}$ Ressalve-se a compreensão de H. L. A. Hart, ao sustentar que, ao lado das normas que denomina primárias, estatuidoras de deveres, existem normas secundárias, estatuidoras de poderes. HART, H. L. A., id., p. 105. Nada obstante, mesmo as normas por ele denominadas secundárias, ou seja, as normas que permitem a introdução de novas normas no sistema, ou a modificação das preexistentes, ou sua extinção, e assim por diante, também podem estabelecer formas e também podem ser resguardadas por sanções como a invalidade. A noção hartiana de normas de reconhecimento afasta-se da hipótese aqui sustentada, pois se compreende seu sentido, mas não se pode conceber que mesmo normas secundárias, no sentido hartiano, sejam desprovidas de sanção. Uma lei elaborada com violação do processo legislativo preconizado ou um ato jurídico privado praticado com inobservância do direito são sancionados com invalidade, como se verá.

${ }^{6}$ E mais adiante, Bobbio evidencia a solução ad hoc encontrada para salvaguardar o paradigma: “A presença de normas não sancionadas em um ordenamento jurídico é um fato incontestável. A solução para esta dificuldade, por parte de quem considera a sanção como elemento constitutivo do direito, não é certamente a de negar o fato. O fato é o que é. Trata-se, quando muito, de ver o direito como conjunto de regras com sanção organizada.” Ou seja, alega-se que, embora algumas normas não possuam sanção específica, o ordenamento tomado em seu conjunto é sancionado e, portanto, garantido.
} 
Para não extrapolar o objeto proposto para o presente artigo com objeto mais ousado e amplo, resta abordar a questão da sanção das normas constitucionais, relegando a importante discussão sobre a existência ou inexistência de normas jurídicas infraconstitucionais desprovidas de sanção para outra oportunidade.

\section{NORMAS CONSTITUCIONAIS E SANÇÃO}

Não é raro encontrar autores que afirmam a existência de normas constitucionais desprovidas de sanção. Entre os exemplos com que pretende ilustrar a existência de normas jurídicas desprovidas de sanção com as normas constitucionais, Norberto Bobbio afirma que uma de suas espécies mais típicas ou comuns seriam aquelas

“(...) normas estabelecidas por autoridade tão alta na hierarquia das normas que se torna impossível, ou pelo menos pouco eficiente, a aplicação de uma sanção. (...) A falta de sanção não depende de um defeito do sistema no seu conjunto, mas de circunstâncias específicas das normas singulares, circunstâncias que tornam, naquele determinado caso, e só nele, ou inútil ou impossível a aplicação de uma sanção, sem que, por outro lado, seja afetado o princípio que inspira o acionamento do mecanismo da sanção, ou seja, o princípio da eficácia reforçada, que vale quando esta eficácia reforçada é possível, e quando, sendo possível, é também necessária ou, pelo menos, particularmente útil.” (BOBBIO, 2005, p.167-168).

Segundo Bobbio, tal é o caso exatamente das normas constitucionais, fato este explorado pelas correntes não-sancionistas, posto tratarem-se das normas mais importantes do ordenamento jurídico (BOBBIO, 2005, p.168). Buscando explicar o fenômeno, o jusfilósofo italiano procura esclarecer:

“É (...) de todo natural que conforme passamos das normas inferiores às superiores, nos aproximamos das fontes de poder, e por isso diminui a carga de autoridade entre quem estabelece a norma e quem deve segui-la, o aparato coercitivo perde vigor e eficiência, até que, chegando às fontes do próprio poder, isto é, ao poder supremo (como o que se denomina 'constituinte'), uma força coercitiva não é absolutamente mais possível, pela contradição que não o consente, ou seja, porque se esta força existissem aquele poder não seria mais supremo.”(BOBBIO, 2005, p.168). 
A explicação para tal fato, o mais das vezes, prende-se à hierarquia das normas constitucionais: como se acaba de demonstrar, Bobbio afirma em sua Teoria da norma jurídica que o fato de algumas normas constitucionais não possuírem sanção não deveria espantar, posto que, estando no ápice do sistema normativo e, portanto, tendo como destinatários os detentores do poder e, muitas vezes, seus próprios criadores, isto seria natural (BOBBIO, 2005, p.169) ${ }^{7}$ Tal explicação sociológica, embora bastante plausível, não deixa de preocupar e causar certa inquietação, ao menos em que adota uma visão constitucionalista do Direito, no sentido télico de que o Direito Constitucional é garantista (TAVARES, 2005, p. 64 e ss.) e busca a limitação do poder. (KELSEN, 2003, p.60 e ss.) ${ }^{8}$

Primeiramente: caso alguém se filie à posição segundo a qual a sanção é essencial à juridicidade, de modo que a inexistência de sanção induz à inexistência da própria norma jurídica, como sustentar, ainda, a juridicidade das normas constitucionais “desprovidas de sanção”? (HART, 2009, p.281)

De outra parte, parece difícil conciliar tal visão com aquela sustentada pelas novas correntes do constitucionalismo, ou os ditos neoconstitucionalismos, especificamente aquelas que sustentam a noção de força normativa da Constituição, a máxima efetividade das normas da Constituição e a eficácia de todas as normas constitucionais.

\footnotetext{
${ }^{7}$ Bobbio chega mesmo a afirmar que no ápice do poder a atuação em desconformidade com uma norma jurídica não constitui sua violação, mas a produção de uma nova norma jurídica, uma modificação no sistema, chegando a exemplificar que a violação do artigo 139 da Constituição Itália de 1948, que veda a reforma da forma republicana de Estado mesmo por emenda constitucional, não haveria violação, mas simplesmente a criação de uma nova Constituição. A despeito da autoridade do autor e do realismo de suas colocações, de ponto de vista constitucionalista atual não se pode transigir com tal visão.

${ }^{8}$ A explicação de Kelsen igualmente não convence. Sustenta o mesmo ao abordar o problema da existência de deveres jurídicos sem sanção e, mais especificamente, a questão das normas constitucionais, que referidas normas seriam "não-autônomas", ou sancionadas indiretamente: "As normas da Constituição que regulam o processo legislativo não estatuem - argumenta-se - quaisquer sanções para a hipótese de não serem observadas. Uma análise mais detalhada mostra, porém, que se trata de normas não-autônomas que fixam apenas um dos pressupostos sob os quais são de aplicar e executar os atos de coação estatuídos por outras normas." Como veremos, parece equivocada tal compreensão. Recordando que para Kelsen uma norma não-autônoma, no sentido que aqui importa, é aquela que prescreve uma conduta sem estatuir uma sanção ela mesma, sendo a sanção estatuída por outra norma. Para Kelsen, tais normas estão indissociavelmente vinculadas, e a norma que não estatui a sanção para o descumprimento dos deveres jurídicos por ela impostos é não-autônoma relativamente à segunda, que estatui tal sanção.

${ }^{9}$ Cabe, pois, citar trecho da obra de Herbert Hart sobre o Direito Internacional, o qual, mutatis mutandis, aqui se aplica com perfeição: "Afirmar que o direito internacional não é vinculante por carecer de sanções organizadas implica aceitar tacitamente a análise da obrigação contida na teoria de que o direito é essencialmente uma questão de ordem apoiadas em ameaças.”
}

REVISTA DO DIREITO PÚBLICO, Londrina, v.9, n.1, p.163-178, jan./abr.2014 
A aceitação da noção ora analisada dificulta ou impossibilita a distinção do constitucionalismo contemporâneo, normativo, de orientações hoje já reputadas ultrapassadas, que afirmavam em um tempo não muito distante, o caráter de mera exortação, promessa ou declaração de intenções dos textos constitucionais.

Referidas premissas dificultariam distinguir, ainda, o constitucionalismo contemporâneo daquelas posições que, de maneira igualmente ultrapassada, distinguiam diferentes graus de juridicidade entre normas constitucionais, de modo a estabelecer que algumas normas constitucionais seriam verdadeiras normas jurídicas, vinculantes, ao passo que outras normas seriam normas imperfeitas, não vinculantes salvo se complementadas por fontes infraconstitucionais.

Conforme visto, portanto, segundo Bobbio a existência, em qualquer ordenamento jurídico, de normas desprovidas de sanção seria um fato inegável. Então resta indagar se acaso realmente existiriam normas constitucionais destituídas de sanção (HART, 2009, p.103-104) ${ }^{10}$.

\section{INCONSTITUCIONALIDADE E INVALIDADE COMO SANÇÕES}

Como sabemos, vige nos sistemas constitucionais o princípio da supremacia ou supralegalidade constitucional, denominado, ainda, princípio da constitucionalidade. Segundo tal princípio, basilar ao constitucionalismo e ancorado na compreensão da hierarquia normativa do sistema jurídico, aos órgãos legislativo com competência infraconstitucional é defeso ofender normas constitucionais, seja procedimentalmente, seja materialmente.

Em outras palavras, por tal princípio, a legislação infraconstitucional deve adequar-se coerentemente para com a legislação constitucional, formal e materialmente.

\footnotetext{
${ }^{10}$ Sem prejuízo da argumentação que será desenvolvida adiante, de se ressaltar que, como observa Hart, "há outros tipos de lei ou modalidades de direito, especialmente as que outorgam poderes jurídicos para exarar decisões ou legislar (poderes públicos), ou para criar ou modificar relações jurídicas (poderes particulares) - modalidades essas que não podem, por absurdo, ser assimiladas às ordens apoiadas em ameaça.” Nada obstante, embora a sanção como ameaça de uso da força esteja, em princípio, afastada de ambas as hipóteses, sanções de invalidade existem e são aplicáveis tanto aos atos legislativos quanto aos atos jurídicos de particulares.
} 
Em caso de ferimento de norma constitucional por norma infraconstitucional, seja por ação, seja por omissão, está-se diante de uma situação de inconstitucionalidade, para a qual os diferentes ordenamentos jurídicos estabelecem o remédio do controle de constitucionalidade, nas mais variadas matizes e variações. ${ }^{11}$

O controle de constitucionalidade visa expungir do ordenamento jurídico a norma ou ato inconstitucionais. A rigor, a se seguir a teoria norteamericana, tal "norma” sequer é uma verdadeira norma, mas um simulacro "null and void”, ou seja, nula e vazia e, portanto, privado de efeitos desde sua origem, razão do efeito em regra retroativo da declaração de inconstitucionalidade e da restituição do status quo ante que dela deve, em regra, decorrer. (KELSEN, 1986, p.329-330) ${ }^{12}$

Ou seja, efeito da inconstitucionalidade é a invalidade, mais precisamente, a nulidade, ainda que, diante de fenômenos como a modulação seja uma nulidade de caráter especial (FERRAZ JÚNIOR, 2007, p.216) ${ }^{13}$. A norma inconstitucional não pertence ao ordenamento jurídico, ao sistema normativo em questão, não sendo por ele reconhecida como norma.

Parece bastante evidente que a cominação de invalidade é uma sanção jurídica. No âmbito do direito privado, por exemplo, a Teoria das Invalidades abrange o estudo das nulidades e das anulabilidades (CANOTILHO, 2003,

\footnotetext{
${ }^{11}$ Diferentemente das correntes convencionais, é possível identificar, com base em Mauro Cappelletti, pelo menos quatro modelos básicos de controle judicial: norte-americano (difuso), austríaco (concentrado), concentrado-mitigado (ítalo-alemão) e latino-americano (misto).

${ }^{12}$ A relação entre hierarquia das normas e validade das normas emana, com toda a transparência, nas seguintes páginas de Hans Kelsen em sua Teoria Geral das Normas: "Que a validade de uma norma fundamenta a validade de uma outra norma, de um modo ou de outro, constitui a revelação entre uma norma superior e uma inferior. Uma norma está em relação com outra norma; a superior em relação com uma inferior, se a validade desta é fundamentada pela validade daquela. A validade da norma inferior é fundamentada pela validade da norma superior pela circunstância de que a norma inferior foi produzida como prescreve a norma superior, pois a norma superior, em relação com a inferior, tem o caráter de Constituição, pois que a natureza da Constituição existe na regulação da produção de normas.” Donde a consequência do descumprimento dos preceitos constitucionais é a invalidade.

${ }^{13}$ Assim, p. ex., Tércio Sampaio Ferraz Júnior: "Normas produzem efeitos. São dotadas de eficácia técnica. Essa capacidade de produzir efeitos, contudo, quando a norma não tem validade, pode ser-lhe recusada desde o momento em que passaria a ter vigência, sendo-lhe a capacidade de produzir efeitos negada ex tunc (desde então). Falamos, nesse caso, de nulidade. Assim, por exemplo, uma lei aprovada e promulgada contra os ditames constitucionais diz-se nula no sentido de que seus efeitos são desconsiderados desde o momento em que começou a viger" (destaques do original).
} 
p. 949-950 $)^{14}$, como é sabido, e a doutrina é uníssona em reconhecer que as invalidades são sanções que retiram a validade de um ato ou negócio jurídico (MONTORO, 2005, p.540). ${ }^{15}$

Neste ponto convém indagar-se qual seria o fundamento para se sustentar em no Direito Público e no Direito Constitucional a invalidade não constituiria uma sanção.

A invalidade decorrente da declaração de inconstitucionalidade fulmina o ato normativo, retirando-o do ordenamento jurídico, seja com eficácia ex tunc (regra nos sistemas americano, italiano, alemão e brasileiro, p. ex.) ou com eficácia ex nunc (regra no sistema austríaco), conforme considere a inconstitucionalidade como uma causa de nulidade ou anulabilidade, respectivamente, como observa Mauro Cappelletti. ${ }^{16}$

No caso brasileiro, inclusive, os efeitos da sanção da invalidade compreendem a retirada do ato inconstitucional do mundo jurídico com efeitos retroativos, o que significa, com o desfazimento dos atos com base nele praticados, salvo modulação. Compreendem, ainda, oponibilidade erga omnes

\footnotetext{
${ }^{14}$ Abstemo-nos aqui de fazer as conhecidas digressões sobre as distinções entre inexistência, invalidade, anulabilidade, nulidade absoluta e nulidade relativa. Porém, convém consignar as considerações de José Joaquim Gomes Canotilho, no sentido de que “a figura unitária da inconstitucionalidade não constitui um ponto de partida satisfatório para uma abordagem da teoria das nulidades em direito constitucional. Uma lei inconstitucional é nula em que sentido: no sentido de inexistência ou de nulidade? No sentido da nulidade absoluta, radical ou de pleno direito ou no sentido de anulabilidade ou nulidade relativa?”. Para uma explanação do tema das nulidades no Direito Constitucional remetemos à referida obra, p. 949 e ss., nas quais Canotilho distinguirá as questões da ineficácia e da inexistência, da anulabilidade e da anulabilidade no Direito Administrativo e no Direito Constitucional.

${ }^{15}$ Montoro, por exemplo, arrola a nulidade como espécie do gênero sanção. Embora a arrole inicialmente como sanção civil, aduz mais adiante que "com características semelhantes, mas adaptadas às peculiaridades dos demais ramos do direito, existem, ainda, sanções fiscais, comerciais, relativas à relação de trabalho, etc.” (MONTORO, 2005, p.541). Assim, a invalidade decorrente da inconstitucionalidade (nulidade, em nosso juízo), tem suas peculiaridades (modulação dos efeitos, p. ex.).

${ }^{16}$ Recordando-se, por oportuno, a classificação das normas com base em seu autorizamento, em mais que perfeitas - aquelas que sancionam sua violação com nulidade do ato praticado em desconformidade com seus preceitos, restituição do status quo ante e ainda aplicação de pena ao violador -, perfeitas - aquelas que sancionam sua violação com nulidade ou anulabilidade do ato desconforme, sem aplicação de pena ao violador -, menos que perfeitas - as que autorizam apenas a aplicação de pena ao violador, sem nulidade ou anulação do ato - e, ao final, imperfeitas - aquelas cuja violação não acarreta consequências. De todas as descrições, a que melhor se enquadra nas normas constitucionais é a de normas perfeitas (nulidade no sistema americano, anulabilidade no sistema austríaco, sem aplicação de penalidade à autoridade responsável por sua edição). No entanto, a visão simplista que busca um preceito secundário expresso cria a ilusão de tratarem-se as normas constitucionais de normas imperfeitas, desprovidas de consequências jurídicas para seu descumprimento. (DINIZ, 2000, p.377-378).
} 
e efeito vinculante relativamente à administração pública e ao Poder Judiciário, em todos os níveis, em caso de controle abstrato, bem como a possibilidade de extensão dos efeitos do controle incidental na forma do art. 52, X, da Constituição Federal.

Salvo melhor juízo, tal sanção é bastante gravosa, e não há preceito constitucional dela desprovido. Mesmo normas aparentemente declaratórias, como, exemplificativamente, as que determinam que Brasília é a capital federal ou que a língua portuguesa é o idioma oficial da República, são dotadas da sanção da inconstitucionalidade, de modo que se uma lei infraconstitucional violar o preceito constitucional será inconstitucional e, portanto, inválida.

Invalidade no plano do dever (Sollen) é equivalente à inexistência no plano do ser (Sein), de modo que, no âmbito jurídico-normativo, principalmente tratando-se da produção das normas jurídicas, é a sanção mais gravosa que se pode cominar.

Resta aduzir alguns argumentos adicionais antes de concluir. Primeiramente parece um tanto absurdo pretender que a Constituição, para ser reconhecida como norma e para ser provida de sanção, fosse estabelecida, por exemplo, nos moldes do Código Penal, em termos de estruturação do binômio preceito primário-preceito secundário, por exemplo, é um patente absurdo (MONTORO, 2005, p.539). ${ }^{17}$ Esta não é a única técnica legislativa possível, e é a própria supremacia da constituição que estabelecem a forma específica de sanção de todas as normas constitucionais.

Como observa o próprio Kelsen, diversas são as possíveis formulações legislativas dos dispositivos, que não se confundem com as normas

\footnotetext{
${ }^{17}$ Como observa Montoro, “a norma primária está, muitas vezes, implícita ou subentendida. O Código Penal, por exemplo, contém em regra apenas normas sancionadoras ou secundárias, deixando implícita a norma primária correspondente. Assim, o art. 129 que dispõe sobre a lesão corporal, tem a seguinte redação: 'Ofender a integridade corporal ou a saúde de outrem; Pena - detenção, de três meses a um ano'. É a norma sancionadora ou secundária. A norma primária está implícita: ‘Toda pessoa deve respeitar a integridade corporal e a saúde de outrem', ou, de forma mais precisa, 'toda pessoa tem o dever jurídico de respeitar a integridade corporal e a saúde de outrem.'.” Pois bem, no Direito Constitucional dá-se o oposto: suas normas em geral estabelecem preceitos primários, sem ostensivamente estabelecerem preceitos secundários, o que não induz à conclusão de que tais preceitos não existam. Pelo contrário: existem e são decorrência direta, imediata e necessária do próprio postulado da constitucionalidade. Afirmar que no Direito Constitucional não há sanções pela ausência explícita ou expressa de preceitos secundários nos dispositivos da Constituição equivale ao absurdo de afirmar que inexistem preceitos primários no Código Penal.
} 
propriamente ditas (TAVARES, 2005, p.271), que deles são extraídas necessariamente após a mediação do intérprete. Nas palavras do austríaco

"Se se admite que a distinção de uma norma que prescreve uma conduta determinada e de uma norma que prescreve uma sanção para o fato da violação da primeira seja essencial para o Direito, então precisa-se qualificar a primeira como norma primária e a segunda como secundária - e não o contrário, como foi por mim anteriormente formulado. A norma primária pode, pois, aparecer inteiramente independente da norma secundária. Mas também é possível que uma norma expressamente formulada, a primeira, i.e., a norma que impõe uma conduta determinada geralmente não apareça, e apenas apareça a norma secundária, i.e., a norma que estabelece a sanção. Desta forma formularam-se reiteradamente normas jurídicas nas modernas leis.” (KELSEN, 1986, p.181).

Exigir que a sanção seja estabelecida para cada norma constitucional expressamente equivale a não distinguir dispositivo de norma jurídica, o que é inadmissível diante do estado da arte. Mais adiante, o expoente da Escola de Viena é ainda mais claro:

“O moderno legislador do Direito não diz: 1. 'Não se deve furtar’ e 2. ‘Se alguém furta deve ser punido com cadeia, ou: 1. 'Deve-se pagar um empréstimo recebido’ e 2. 'Se alguém não paga um empréstimo recebido, deve ser dirigida uma execução em seu patrimônio’, mas ele se limita, comumente, a estabelecer a norma que liga ao furto a sanção da pena de prisão, ou o não-pagamento de um empréstimo recebido a sanção da execução forçada. A expressa formulação da norma que proíbe o furto e da norma que impõe o pagamento de um empréstimo recebido, i.e., a norma que prescreve a conduta que evita a sanção é efetivamente supérflua, pois está - como já indicado anteriormente - implicada na norma que estatui a sanção.” (KELSEN, 1986, p.181-182).

Do mesmo modo que o legislador ordinário tem utilizado, como observado por Hans Kelsen, a técnica legislativa consistente em redigir apenas e tão-somente a consequência jurídica do descumprimento dos deveres, em matéria penal, por exemplo, o legislador constituinte tem, em regra, optado pelo caminho oposto: estabelece os princípios fundamentais da ordem jurídica, as normas basilares que devem reger por inteiro o conjunto do ordenamento, abstendo-se de estabelecer em cada dispositivo expressamente expressões como "sob pena de inconstitucionalidade", ou 
“sob pena de invalidade” ou ainda "sob pena da nulidade”, por absolutamente desnecessário (TAVARES, 2005, p.57). ${ }^{18}$

Utilizando o mesmo raciocínio de Kelsen, tal técnica legislativa seria despicienda, e o estabelecimento, neste caso, do preceito secundário (sanção) seria supérfluo, além de repetitivo, posto que a sanção é sempre a mesma.

E mais, do mesmo modo que no exemplo do expoente da Escola de Viena o preceito primário está implicado no preceito secundário, o inverso é verdadeiro quanto às Constituições: nelas, o preceito secundário (sanção, nulidade) está implicado no preceito primário (comando deôntico).

Ainda deve-se aduzir que o próprio autor da Escola de Viena, apesar de dizer que as normas constitucionais seriam normas "não-autônomas" reconhece, na Teoria Pura, a consequência que decorre de seu descumprimento, que aqui são interpretadas como sanções jurídicas na acepção plena do termo. ${ }^{19}$

Acrescente-se ainda que embora Bobbio afirme que a sanção está relacionada com a eficácia da norma, e não com sua validade (BOBBIO, 2005, p.167), deve-se observar que isto é verdadeiro apenas em parte. Se considerarmos a assertiva tendo em mente normas jurídicas em geral, a afirmativa está correta. A norma é juridicamente válida seja eficaz ou não, e a sanção existe para resguardar a eficácia da norma.

No entanto, se observarmos o prisma a partir da ideia de metanormas, ou normas de sobredireito, como, p. ex., as existentes na Constituição relativas à produção do próprio direito, referentes ao processo legislativo - bem como todas as normas constitucionais, mesmo que indiretamente, dizem respeito à produção do direito infraconstitucional -, fica claro que a sanção passa a relacionar-se com a validade no nível constitucional (CANOTILHO, 2003, p.693). ${ }^{20}$

\footnotetext{
${ }^{18}$ Salvo dispositivos excepcionais, como o art. 93, IX, da Constituição Federal. A Constituição é, antes de tudo, norma de sobredireito. Como observa o autor "A Constituição contém os preceitos básicos de produção das demais normas pelo próprio sistema. Regula-se, pois, a produção normativa do Direito pelo próprio Direito.” (TAVARES: 2005, p. 57).

19 "Se as determinações da Constituição não são respeitadas, então não se produzem quaisquer normas jurídicas válidas, as normas em tais condições produzidas são nulas ou anuláveis, isto é: o sentido subjetivo dos atos postos inconstitucionalmente e que, portanto, não são postos de acordo com a norma fundamental, não será interpretado como seu sentido objetivo ou, então, essa interpretação provisória - vem a ser repudiada.” (KELSEN, 2003, p.57)

${ }^{20}$ Como observa Canotilho, a Constituição deve ser compreendida como uma norma primária reguladora da produção jurídica, identificando suas funções, no particular, no sentido de identificar as fontes do direito, estabelecer os critérios de validade e eficácia de cada fonte e de determinar a competência jurígena das entidades ou órgãos. Ibid.
} 
Assim, o descumprimento do processo legislativo constitucionalmente estabelecido - iniciativa, trâmite, turnos, quóruns e outros requisitos estabelecidos para as diversas espécies normativas - implica a sanção da invalidade, decorrência da inconstitucionalidade formal. ${ }^{21}$

Por outro lado, estatuindo a Constituição limites materiais à discricionariedade legislativa, igualmente a sanção pelo descumprimento dos limites constitucionais implica sanção de invalidade, decorrência de inconstitucionalidade material.

Assim, em síntese, no nível das normas constitucionais a sanção relaciona-se imediatamente com a validade e mediatamente com a eficácia, donde neste nível pode-se afirmar que a sanção volta-se para o campo da validade (HART, 2009, p.136-137). ${ }^{22}$

No mesmo sentido, embasando a interpretação da invalidade decorrente da inconstitucionalidade como uma sanção geral a ser aplicada pelos mecanismos de controle de constitucionalidade, o magistério de José Joaquim Gomes Canotilho, no seguinte sentido:

"Se o controlo da constitucionalidade dos actos normativos é um dos meios de defesa e garantia da força normativa da constituição, justificase que, para ele ser efectivo e eficaz, as violações das normas e princípios constitucionais captadas em sede de fiscalização judicial sejam acompanhadas de sanções adequadas. Trata-se, pois, de saber qual a reacção da constituição perante actos normativos comprovadamente desconformes com as suas normas e princípios. O princípio da prevalência da constituição não deixa margem para dúvidas relativamente à sanção geral aplicável a um acto normativo colidente com o parâmetro normativoconstitucional - inconstitucionalidade.” (CANOTILHO, 2003, p.947).

\footnotetext{
${ }^{21}$ Embora Hart vislumbre a questão da sanção diretamente relacionada com as normas que impõe deveres (normas primárias em sua terminologia) e não com as normas que criam poderes (secundárias em sua terminologia), a sua ideia de norma de reconhecimento pode ser útil à compreensão do que se está aqui a dizer: "Podemos afirmar que um critério de validade jurídica ou fonte do direito é supremo se as normas identificadas mediante referência a ele são ainda reconhecidas como normas do sistema mesmo que conflitem com outras normas identificadas mediante referência aos outros critérios; enquanto estas últimas não são reconhecidas caso conflitem com as primeiras, identificadas mediante referência ao critério supremo”. (HART, 2009, p. 136-137). Sobre as limitações constitucionais e o não-reconhecimento de validade ou juridicidade de normas.

${ }^{22}$ Ou poderíamos ousar afirmar, utilizando uma construção kelseniana, que o campo da eficácia da norma constitucional constitui o campo da validade do direito infraconstitucional, em um primeiro momento.
} 
Em síntese, os postulados da supremacia da constituição e da constitucionalidade das leis implicam a cominação de uma sanção a todo e qualquer ato normativo que contravenha disposições constitucionais, a saber, a sanção da invalidade, o que esvazia, em nosso ver, as teorizações sobre normas constitucionais desprovidas de sanção.

\section{CONSIDERAÇÕES FINAIS}

Com o presente estudo espera-se pelo menos causar inquietação quanto à afirmativa simplista corriqueiramente repetida no sentido da existência de normas constitucionais desprovidas de sanção, bem como quanto às explicações ensaiadas para justificar tal situação, que se reputa aparente, como visto.

A despeito do aparente realismo das explicações sociologistas a respeito da existência de normas desprovidas de sanção, especialmente normas constitucionais, deve-se evidenciar que tal visão pode ser perniciosa para a noção de força normativa da constituição e dificilmente conciliável com as orientações teóricas que perfilham tal orientação.

Apesar de constituir uma orientação bastante normativista, a concepção aqui esposada, no sentido de considerar que toda norma constitucional necessariamente encontra apoio na sanção da inconstitucionalidade parece mais consistente com as tendências atuais do Direito Constitucional, e mais consequente quanto à afirmação da densidade normativa das normas constitucionais.

Assim, sustenta-se que a definição de que a nulidade ou anulabilidade, conforme a orientação teórica prevalente, decorrente da inconstitucionalidade consiste em uma sanção genérica, nas palavras de Canotilho, sanção esta que está a assegurar a eficácia de toda e qualquer norma constitucional, sancionando as normas contrárias no plano da validade.

Tal concepção afasta a propalada existência de normas constitucionais desprovidas de sanção, por um lado, e, por outro, não afasta a possibilidade de adoção de sanções específicas voltadas contra as autoridades responsáveis pela criação de atos inconstitucionais (TAVARES, 2005, p.78). 


\section{REFERÊNCIAS}

BOBBIO, Norberto. Teoria da Norma Jurídica. Trad. Fernando P. Baptista e Ariani B. Sudatti. 3. ed. rev. São Paulo: Edipro, 2005.

. Teoria do Ordenamento Jurídico. Trad. Maria C. C. Santos. 10. ed. Brasília: Editora UnB, 1999.

CANOTILHO, José Joaquim Gomes. Direito Constitucional e Teoria da Constituição. 7. ed. Coimbra: Almedina, 2003.

DINIZ, Maria Helena. Compêndio de Introdução à Ciência do Direito. 12. ed. São Paulo: Saraiva, 2000.

FERRAZ JUNIOR, Tércio Sampaio. Introdução ao Estudo do Direito: técnica, decisão, dominação. 5. ed. rev. e ampl. São Paulo: Atlas, 2007.

HART, Herbert L. A. O conceito de Direito. Trad. Antônio de Oliveira Sette-Câmara. São Paulo: Martins Fontes, 2009.

KELSEN, Hans. Teoria Geral das Normas. Trad. José Florentino Duarte. Porto Alegre: Sergio AntonioFabris:1986.

. Teoria Pura do Direito. Trad. João B. Machado. São Paulo: Martins Fontes, 2003.

MONTORO, André Franco. Introdução à Ciência do Direito. 26. ed. rev. e atual. São Paulo: Revista dos Tribunais, 2005.

TAVARES, André Ramos. Teoria da Justiça Constitucional. São Paulo: Saraiva, 2005. 
Como citar: SGARBOSSA, Luís Fernando. IENSUE, Geziela. Existem normas constitucionais desprovidas de sanção? Revista do Direito Público. Londrina, v.9, n.1, p.163-178, jan./abr.2014. DOI: 10.5433/1980511X.2014v9n1p163. 